\title{
Ra-SBRT is Potential Immune Adjuvant for Innate Immune Cell Populations in Advance Stage NSCLC Patients
}

\author{
Arun Chairmadurai ${ }^{1,2}$, Harish Chandra Goel ${ }^{2}$, Sandeep Jain ${ }^{1,3}$, Aklank Jain ${ }^{4}$ and \\ Hridayesh Prakash ${ }^{5, *}$
}

${ }^{1}$ Jaypee Hospital, Sector -128, NOIDA, UP, India

${ }^{2}$ Amity Centre for Radiation Biology, Amity University, Uttar Pradesh, Sector -125, NOIDA, India

${ }^{3}$ Department of Radiotherapy, The Brunei Cancer Centre, Pantai Jerudong Specialist centre, Brunei

${ }^{4}$ Department of Zoology, Central University of Punjab, Bhatinda, Punjab, India

${ }^{5}$ Amity Institute of Virology and Immunology, Amity University, Uttar Pradesh, Sector -125, NOIDA, India

\begin{abstract}
Bystander toxicity and tissue fibrosis are the major complications with conventional radiation therapy for cancer patients. In this context, we here propose RapidArc - Stereotactic Body Radiation Therapy (Ra-SBRT) as a noninvasive and immune adjuvant approach for the successful eradication of advance stage NSCLC. Ra-SBRT is highly focused and capable of destroying tumors with high grade metastatic lesions and spared normal tissues. Follow up of stage $4^{\text {th }}$ NSCLC patient revealed that Ra-SBRT is potentially immunogenic which was evident by increased number of iNOS+ Tumor Associated macrophages (M1-TAM), Siglac-8+ eosinophils, basophils and subsequent prolongation of disease free survival of $4^{\text {th }}$ stage NSCLC patients by 3 years. This study demonstrated M1 retuning potential of Ra-SBRT which is a pre-requisite of effective management of inoperable and highly metastatic tumors of lung with least or no bystander impact.
\end{abstract}

Keywords: SBRT, lung cancer, iNOS+ macrophage, Eosinophils, Innate Immunity.

\section{INTRODUCTION}

RapidArc- Stereotactic body radiotherapy (RaSBRT) is a noninvasive approach [1] for delivering ablative dose to tumor while sparing neighboring normal tissues which are associated with conventional radiotherapy [2-6] of tumor. Due to non-invasive nature of SBRT, it has become as indispensible modality for the management of high grade metastatic NSCLC and lung adenocarcinoma [7-11]. SBRT reduces toxicity to normal tissue and enhances the quality of post treatment life of NSCLC patients [12-14]. With this mandate we conducted a prospective study with NSCLC patients with high grade metastatic lesions. The study was approved on tumor board meeting and all procedures in studies involving human participants were performed in accordance with the ethical standards of the Institutional Review Board (IRB) and 1964 Declaration of Helsinki and its later amendments. All patients in this study had around 11 lung lesions, of which six were peripherally located and five were located centrally. Respiratory movement is the major constraints for the therapy outcome of SBRT and requires abdominal compression which improved TCP up to $15 \%$ and reduced the volume of PTVs to $42 \%$

*Address correspondence to this author at the Amity Institute of Virology and Immunology, Amity University, Sector-125, NOIDA, (National Capital Region), India; Tel: +91-120-4392961; E-mail: hprakash@amity.edu and $57 \%$ among 6 peripherally and 5 centrally located lung lesions respectively. In peripheral lung lesions, TCP got significantly enhanced to $0.6 \%$ for long-term (>5years; $p<0.05$ ), and NTCP was significantly reduced in patients with Grade $\geq$ II pneumonitis $(0.2 \%$; $p<0.05)$. Although, in central lung lesions, TCP got enhanced insignificantly however NTCPs got reduced significantly [15] for cartilage necrosis and myelitis. Post treatment follow up of patient using positron emission tomography fused with computed tomography up to 12 months post treatment revealed no residual tumors in the treatment beds of any of the patient analyzed as per the Response Evaluation Criteria. However one patient developed asymptomatic lung pneumonitis (ALP) in the dose fall-off region during his six-month follow-up. However, his ALP decreased extensively over the next six months and patient survived for more than three years. The primary outcome criterion of this study was to evaluate response of NSCLC patients toward SBRT treatment and to compare tumor control. The secondary outcome criterion was to compare overall survival post therapy. Tumor control Probability (TCP) was calculated using Poisson's linear quadratic (PLQ) cell survival model $[16,17]$ and normal tissue complication probability (NTCP) was calculated using Lyman-Kutcher-Burman (LKB) cell survival model [1821]. Internal treatment volume (ITV) within which the tumor moves within thoracic region was also monitored. Based on delineating ITV, SBRT was 
delivered to tumors [15] which reduced bystander toxicity by $15 \%$. Combining RapidArc technique with SBRT reduced the exposure time and toxicity to normal tissues with rapid exponential dose fall-off than [22-25] conventional radiotherapy techniques. On the basis of this; we analyzed the therapeutic influence of RapidArc in SBRT for NSCLC. In the study we included TCP and NTCP prospectively for yielding better clinical outcome. In our study, treatment set-up variations were restricted with abdominal compression device and patients were comfortable for $6 \mathrm{MV}$ (CF) at a dose rate of 600 $\mathrm{MU} / \mathrm{min}$. Biological equivalent dose was reduced by $0.5 \%$ and exposure time was increased from $2 \mathrm{~min}$ to $10 \mathrm{~min}$ for delivering 10Gyper fraction [26] for the study.

\section{RESULTS AND DISCUSSION}

Cell survival probability curve analysis from NSCLC patients; delivered with 50Gy by SBRT revealed TCP $95.70 \pm 0.12 \%$ for 3 -year and $92.37 \pm 0.19 \%$ for long term on peripherally located lung lesions (Table 1). Similarly, TCP was $95.76 \pm 0.06 \%$ for 3 -years and $92.48 \pm 0.09 \%$ for centrally located lung lesions. Tissue complication probability for the patients which underwent $6 \mathrm{MV}$ RapidArc-SBRT was also recorded. TCP for high grade Pnuemonitis was $1.00 \pm 0.25 \%$ and $0.96 \pm 0.51 \%$; Pathologic rib fracture was $36.98 \pm 32.64 \%$ and $36.47 \pm 26.83 \%$; Esophagitis was $0.25 \pm 0.10 \%$ and $2.40 \pm 2.30 \%$ on peripherally and centrally located lung lesions respectively. Necrosis of cartilage in trachea was negligible on peripheral and $61.30 \pm 11.33 \%$ (Table 1) on centrally located lung lesions respectively. Interestingly we could not find any correlation of percarditis on both peripherally and centrally located lung lesions in these patients. Most interestingly and following our expectation, follow-up of RapidArc-SBRT treated patients revealed no residual tumors in the treatment beds of any of the NSCLC patient upto one year as per the response evaluation criteria. During follow up, one patient with peripheral lung lesion, developed asymptomatic lung pneumonitis (ALP) during follow-up but cured completely afterward. TCP predictions were further correlated with survival of patient surviving for more than 3-years. Out of 20 patients of $4^{\text {th }}$ stage NSCLC cases, we followed up with one 50-year-old patient who initially had lung adenocarcinoma of $2 \mathrm{~cm} \times 2 \mathrm{~cm} \times 2.5 \mathrm{~cm}$ in size

Table 1: Correlation Analysis of Tumor Control Probability and Normal Tissue Complication Probability for RapidArc Plans on Peripherally and Centrally Located Lung Lesions of NSCLC Patients ( $n=20)$

\begin{tabular}{|c|c|c|c|c|c|c|c|}
\hline \multicolumn{8}{|c|}{ Tumor Control Probability } \\
\hline \multirow{2}{*}{$\begin{array}{l}\text { Target } \\
\text { Volume }\end{array}$} & \multirow{2}{*}{ Local Control } & \multicolumn{3}{|c|}{ Peripheral Lesions } & \multicolumn{3}{|c|}{ Central Lesions } \\
\hline & & $6 \mathrm{MV}(\mathrm{CF})$ & $6 \mathrm{MV}$ (FFF) & $10 \mathrm{MV}$ (FFF) & $6 \mathrm{MV}(\mathrm{CF})$ & $6 \mathrm{MV}$ (FFF) & $10 \mathrm{MV}$ (FFF) \\
\hline GTV & 3 Years & $95.70 \pm 0.12$ & $\begin{array}{c}95.66 \pm 0.10 \\
(p=0.49)\end{array}$ & $\begin{array}{c}95.85 \pm 0.16 \\
(p=0.01)\end{array}$ & $95.76 \pm 0.06$ & $\begin{array}{c}95.76 \pm 0.04 \\
(p=1.00)\end{array}$ & $\begin{array}{c}95.70 \pm 0.08 \\
(p=0.12)\end{array}$ \\
\hline GTV & Long-term & $92.37 \pm 0.19$ & $\begin{array}{c}92.32 \pm 0.16 \\
(p=0.53)\end{array}$ & $\begin{array}{c}92.62 \pm 0.27 \\
(p=0.01)\end{array}$ & $92.48 \pm 0.09$ & $\begin{array}{c}92.52 \pm 0.10 \\
(p=0.53)\end{array}$ & $\begin{array}{c}92.47 \pm 0.15 \\
(p=0.79)\end{array}$ \\
\hline \multicolumn{8}{|c|}{ Normal Tissue Complication Probability } \\
\hline \multirow{2}{*}{$\begin{array}{c}\text { Critical } \\
\text { Organ }\end{array}$} & \multirow{2}{*}{ End Point } & \multicolumn{3}{|c|}{ Peripheral Lesions } & \multicolumn{3}{|c|}{ Central Lesions } \\
\hline & & $6 \mathrm{MV}(\mathrm{CF})$ & $6 \mathrm{MV}$ (FFF) & $10 \mathrm{MV}$ (FFF) & $6 \mathrm{MV}(\mathrm{CF})$ & $6 \mathrm{MV}$ (FFF) & $10 \mathrm{MV}$ (FFF) \\
\hline Lung & $\begin{array}{l}\text { Pnuemonitis, } \\
\text { Grade - } \geq 11\end{array}$ & $1.00 \pm 0.25$ & $\begin{array}{l}0.99 \pm 0.24 \\
(p=0.01)\end{array}$ & $\begin{array}{l}1.04 \pm 0.27 \\
(p=0.01)\end{array}$ & $0.96 \pm 0.51$ & $\begin{array}{l}0.97 \pm 0.52 \\
(p=0.70)\end{array}$ & $\begin{array}{l}0.98 \pm 0.51 \\
(p=0.02)\end{array}$ \\
\hline Rib & Pathologic fracture & $36.98 \pm 32.64$ & $\begin{array}{c}37.12 \pm 32.49 \\
(p=0.68)\end{array}$ & $\begin{array}{c}37.85 \pm 32.72 \\
(p=0.08)\end{array}$ & $36.47 \pm 26.83$ & $\begin{array}{c}47.87 \pm 19.59 \\
(p=0.31)\end{array}$ & $\begin{array}{c}36.13 \pm 26.91 \\
(p=0.59)\end{array}$ \\
\hline Heart & Pericarditis & $0.00 \pm 0.00$ & $\begin{array}{c}0.00 \pm 0.00 \\
(p=n . a)\end{array}$ & $\begin{array}{c}0.00 \pm 0.00 \\
(p=n . a)\end{array}$ & $0.00 \pm 0.00$ & $\begin{array}{c}0.00 \pm 0.00 \\
(p=n . a)\end{array}$ & $\begin{array}{c}0.00 \pm 0.00 \\
(p=n . a)\end{array}$ \\
\hline Trachea & Cartilage necrosis & $0.00 \pm 0.00$ & $\begin{array}{c}0.00 \pm 0.00 \\
(p=n . a)\end{array}$ & $\begin{array}{c}0.00 \pm 0.00 \\
(p=n . a)\end{array}$ & $61.30 \pm 11.33$ & $\begin{array}{c}60.97 \pm 11.23 \\
(p=\text { n.a })\end{array}$ & $\begin{array}{c}62.75 \pm 11.91 \\
\quad(p=n . a)\end{array}$ \\
\hline Esophagus & $\begin{array}{l}\text { Esophagitis, } \\
\text { Grade - } \geq 11\end{array}$ & $0.25 \pm 0.10$ & $\begin{array}{l}0.26 \pm 0.10 \\
(p=0.62)\end{array}$ & $\begin{array}{l}0.28 \pm 0.12 \\
(p=0.19)\end{array}$ & $2.40 \pm 2.30$ & $\begin{array}{l}2.37 \pm 2.39 \\
(p=0.85)\end{array}$ & $\begin{array}{l}2.77 \pm 2.98 \\
(p=0.40)\end{array}$ \\
\hline Spinal Cord & Necrotic Myelitis & $0.00 \pm 0.00$ & $\begin{array}{c}0.00 \pm 0.00 \\
(p=n . a)\end{array}$ & $\begin{array}{c}0.00 \pm 0.00 \\
(p=n . a)\end{array}$ & $26.76 \pm 0.00$ & $\begin{array}{c}30.48 \pm 0.00 \\
(p=n . a)\end{array}$ & $\begin{array}{c}31.46 \pm 0.00 \\
(p=n . a)\end{array}$ \\
\hline
\end{tabular}


affecting the left lower lobe. This was accompanied with aorto-pulmonary and mediastinal nodes measuring $1 \mathrm{~cm}$ each. The patient was referred for SBRT for treating the lung lesion and metastatic nodes. PET / CT scan of this patient during his follow up 30 month post treatment revealed no pleural or pericardial effusion (Figure 1A). Large airways, heart, great vessels and other mediastinal structures appeared normal with no significant abnormal FDG uptake. Most interestingly the lung of this patient had ill-defined fibro-consolidative lesion (Figure 1B).

We have recently demonstrated that Radiation therapy (RT) bears potential of orchestrating innate and adaptive immunity against established tumor of pancreas $[27,28]$ in neo adjuvant setting. Our studies have amply demonstrated that iNOs+ effector macrophages (M1-TAM) are indispensible for RT triggered retuning of tumor microenvironment and subsequent rejection of established and refractory tumors of [27] of pancreas. On the basis of these studies, we anticipated that RapidArc-SBRT would also enhance the density of iNOs+ M1 effector macrophages and enhance immunity of these patients for effective tumor control.Indeed, analysis of all patients which have undergone Ra-SBRT (with high ${ }^{\text {TCP }}$ / low ${ }^{\text {NTCP }}$ ) revealed a clinical correlation with increase in the number of iNOS+ M1-TAM $[27,28]$ and Siglac-8+ Eosinophil [29] populations 6 months post treatment (Figure 1C and Table 2) in these patients which are potentially anti-tumorous in nature. Since M1 TAM and

A

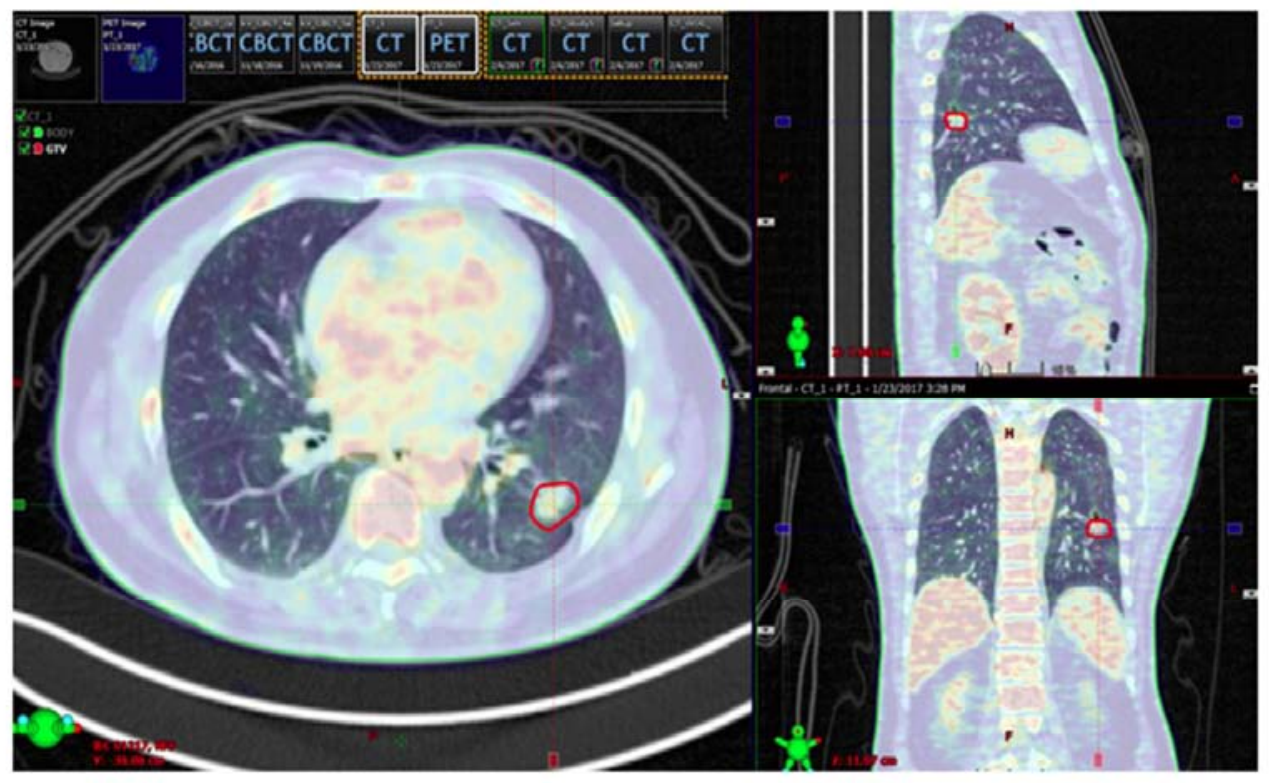

B

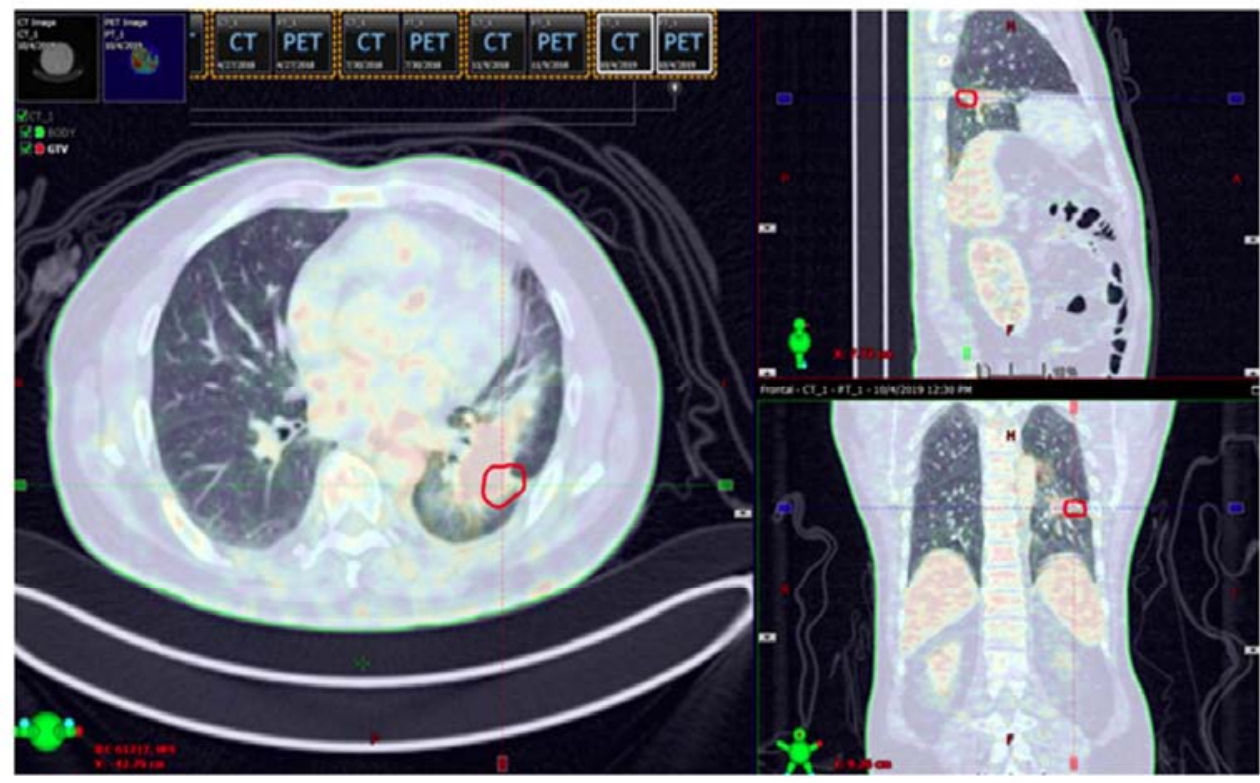


(Figure 1) continued

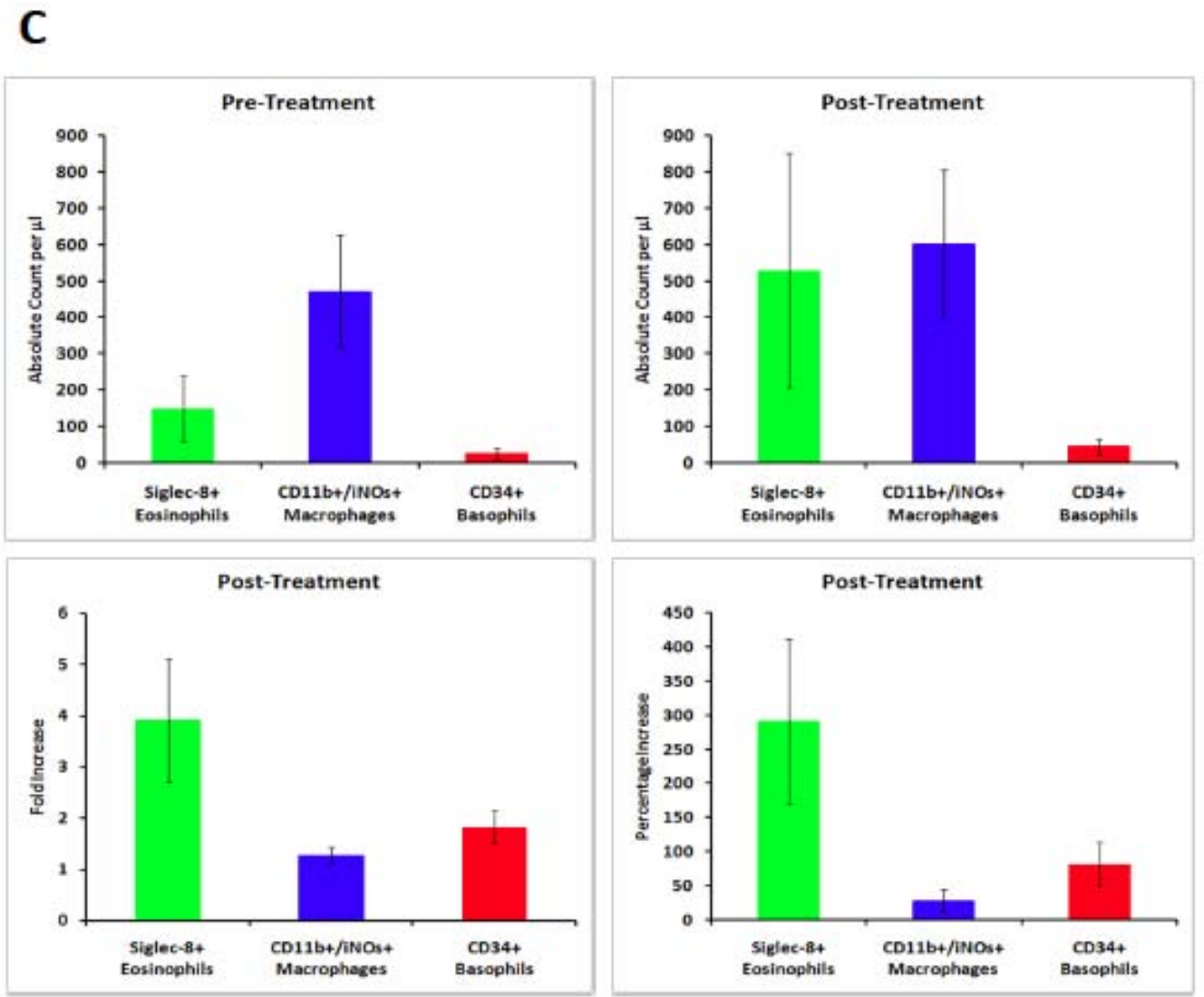

Figure 1: Ra-SBRT is potentially immunogenic and promotes tumor immune rejection in the NSCLC patients.

Shown here is The PET-CT sacn of patients before (A) and during follow up (B) 30 months post treatment (C) Ra-SBRT enhances tumor reactive innate cell populations in NSCLC patients. Shown here is mean of absolute and \% increase in the iNOS+ M1 effector macrophages, Eosinophils and Basophils in NSCLC patients during their follow up. All values were normalized against non-irradiated control patients.

Siglac-8+ eosinophils are potentially immunogenic in nature therefore we believe that elevated number of iNOs+ macrophage [30,31] Siglac-8+ eosinophils [32] populations together could have promoted immunogenic responses in these patients accounting for high TCP in Ra-SBRT patients.

In summary our finding suggest that RapidArcSBRT is one potential cancer directed immune therapeutic modality and have tremendous potential for rescuing patients from death from most aggressive NSCLC.

\section{METHODS}

The work described has been carried out in accordance with the code of Ethics of the World Medical Association as per Declaration of Helsinki. CT datasets were acquired using helical CT machine Biograph (Siemens Healthcare, Erlangen, Germany), at a random phase of shallow breath. These CT datasets were used as baseline datasets for contouring and planning. Gross tumor volumes (GTVs) were contoured by an expert radiation oncologist. Two more CT datasets were acquired at deep inspirational and

Table 2: RapidArc-SBRT Promotes Immune Reconstitution in the NSCLC Patients $(n=20)$ during their Follow Up

\begin{tabular}{|c|c|c|c|}
\hline \multirow{2}{*}{} & \multicolumn{2}{|c|}{ Mean } & \multirow{2}{*}{ P-value } \\
\cline { 2 - 4 } & Pre-Treatment & Post-Treatment & $<0.05$ \\
\hline \hline Siglec-8+Eosinophils & 150.00 & 529.50 & $<0.05$ \\
\hline iNOs+ Macrophages & 474.00 & 603.50 & $<0.05$ \\
\hline CD34+ Basophils & 27.13 & 46.00 & \\
\hline
\end{tabular}


expirational breath hold phases. GTVs were separately contoured on these datasets which were fused together with baseline datasets to generate internal treatment volume (ITV) which was further expanded with 3-mm margin to delineate planning treatment volume (PTV). Critical organs like lungs, ribs, esophagus, trachea, spinal cord, and heart were contoured on baseline CT dataset.The prescribed dose of 50Gy were delivered in 5 fractions to PTV using RapidArc Technique with two co-planar $360^{\circ}$ arcs (first in clockwise $-181^{\circ}$ to $179^{\circ}$ and second in anti-clockwise $-179^{\circ}$ to $181^{\circ}$ ). RapidArc was delivered to patient with $6 \mathrm{MV}$ conventionallyflattened (CF) photon beam of the linear accelerator TrueBeamSTx platform Linac (Varian Medical Systems, Palo Alto, CA) at the maximum dose rate of 600 Monitor units per minute (MU/min), after prospective comparison with $6 \mathrm{MV}$ flattening-filter-free (FFF) and $10 \mathrm{MV}$ (FFF) having maximum dose rate of 1400 and $2400 \mathrm{MU} / \mathrm{min}$ respectively. Radiobiological efficacy of the RapidArc plan was evaluated on the basis of TCP and NTCP which were obtained from dose-volume histograms. PET-CT imagine of the patients who came for follow up was done (Figure 1B) from vertex to mid-thigh were after intravenous injection of $185 \mathrm{MBq}$ of F-18 fluorodeoxyglucose (FDG) on dedicated Biograph mCT scanner. Fusion images of positron emission tomography (PET) and computed tomography $(\mathrm{CT})$ were obtained and reported. For the analysis of myeloid cell compartment of all 20 patients enrolled for the study was done from peripheral blood. PBMC were purified from the blood using Ficoll based method and various cells were purified by MACS based separation system (Miltenyi Biotec) as per manufacture instruction.

\section{AUTHOR CONTRIBUTION}

H.P. Concived the idea and supervised the study; $A C$; conducted the clinical analysis including recruitment of the patients; S.J. Recorded PET-CT scan of the patients and treated them with SBRT; A.J. Editted the manuscript.

\section{ACKNOWLEDGEMENT}

The study was supported by the fund from Radiotherapy unit of Jaypee hospital Approval number - JHN000130511.

\section{CONFLICT OF INTEREST}

The authors have declared that no conflict of interest exists.

\section{REFERENCES}

[1] Tubin S, Popper HH, Brcic L. Novel stereotactic body radiation therapy (SBRT)-based partial tumor irradiation targeting hypoxic segment of bulky tumors (SBRT-PATHY): improvement of the radiotherapy outcome by exploiting the bystander and abscopal effects. Radiat Oncol 2019; 14: 21. https://doi.org/10.1186/s13014-019-1227-y

[2] Marin A, Martin M, Linan $O$, Alvarenga F, Lopez $M$, Fernandez L, Buchser D, Cerezo L. Bystander effects and radiotherapy. Rep Pract Oncol Radiother 2015; 20: 12-21. https://doi.org/10.1016/j.rpor.2014.08.004

[3] Sroussi HY, Epstein JB, Bensadoun RJ, Saunders DP, Lalla RV, Migliorati CA, Heaivilin N, Zumsteg ZS. Common oral complications of head and neck cancer radiation therapy: mucositis, infections, saliva change, fibrosis, sensory dysfunctions, dental caries, periodontal disease, and osteoradionecrosis. Cancer Med 2017; 6: 2918-2931. https://doi.org/10.1002/cam4.1221

[4] Avraham T, Yan A, Zampell JC, Daluvoy SV, HaimovitzFriedman A, Cordeiro AP, Mehrara BJ. Radiation therapy causes loss of dermal lymphatic vessels and interferes with lymphatic function by TGF-beta1-mediated tissue fibrosis. Am J Physiol Cell Physiol 2010; 299: C589-C605. https://doi.org/10.1152/ajpcell.00535.2009

[5] Gunn GB, Anderson KE, Patel AJ, Gallegos J, Hallberg CK, Sood G, Hatch SS, Sanguineti G. Severe radiation therapyrelated soft tissue toxicity in a patient with porphyria cutanea tarda: a literature review. Head Neck 2010; 32: 1112-1117. https://doi.org/10.1002/hed.21161

[6] Kumar S, Kolozsvary A, Kohl R, Lu M, Brown S, Kim JH. Radiation-induced skin injury in the animal model of scleroderma: implications for post-radiotherapy fibrosis. Radiat Oncol 2008; 3: 40.

https://doi.org/10.1186/1748-717X-3-40

[7] Baumann R, Chan MKH, Pyschny F, Stera S, Malzkuhn B, Wurster S, Huttenlocher S, Szucs M, Imhoff D, Keller C, Balermpas P, Rades D, Rodel C, Dunst J, Hildebrandt G, Blanck O. Clinical Results of Mean GTV Dose Optimized Robotic-Guided Stereotactic Body Radiation Therapy for Lung Tumors. Front Oncol 2018; 8: 171.

https://doi.org/10.3389/fonc.2018.00171

[8] Guckenberger M. Dose and Fractionation in Stereotactic Body Radiation Therapy for Stage I Non-Small Cell Lung Cancer: Lessons Learned and Where Do We Go Next? Int J Radiat Oncol Biol Phys 2015; 93: 765-768. https://doi.org/10.1016/j.jirobp.2015.08.025

[9] Xia T, Li H, Sun Q, Wang Y, Fan N, Yu Y, Li P, Chang JY. Promising clinical outcome of stereotactic body radiation therapy for patients with inoperable Stage I/II non-small-cell lung cancer. Int J Radiat Oncol Biol Phys 2006; 66: 117-125. https://doi.org/10.1016/j.ijrobp.2006.04.013

[10] Timmerman R, Heinzerling J, Abdulrahman R, Choy $\mathrm{H}$, Meyer JL. Stereotactic body radiation therapy for thoracic cancers: recommendations for patient selection, setup and therapy. Front Radiat Ther Oncol 2011; 43: 395-411. https://doi.org/10.1159/000322503

[11] Lagerwaard FJ, Haasbeek CJ, Smit EF, Slotman BJ, Senan $\mathrm{S}$. Outcomes of risk-adapted fractionated stereotactic radiotherapy for stage I non-small-cell lung cancer. Int J Radiat Oncol Biol Phys 2008; 70: 685-692. https://doi.org/10.1016/j.ijrobp.2007.10.053

[12] Solda F, Lodge M, Ashley S, Whitington A, Goldstraw P, Brada M. Stereotactic radiotherapy (SABR) for the treatment of primary non-small cell lung cancer; systematic review and comparison with a surgical cohort. Radiother Oncol 2013; 109: 1-7. https://doi.org/10.1016/j.radonc.2013.09.006

[13] Zheng X, Schipper M, Kidwell K, Lin J, Reddy R, Ren Y, Chang A, LV F, Orringer $M$, Spring Kong FM. Survival 
outcome after stereotactic body radiation therapy and surgery for stage I non-small cell lung cancer: a metaanalysis. Int J Radiat Oncol Biol Phys 2014; 90: 603-611. https://doi.org/10.1016/.ijrobp.2014.05.055

[14] Zhang B, Zhu F, Ma X, Tian Y, Cao D, Luo S, Xuan Y, Liu L, Wei Y. Matched-pair comparisons of stereotactic body radiotherapy (SBRT) versus surgery for the treatment of early stage non-small cell lung cancer: a systematic review and meta-analysis. Radiother Oncol 2014; 112: 250-255. https://doi.org/10.1016/j.radonc.2014.08.031

[15] Chairmadurai A, Goel HC, Jain SK, Kumar P. Radiobiological analysis of stereotactic body radiation therapy for an evidence-based planning target volume of the lung using multiphase CT images obtained with a pneumatic abdominal compression apparatus: a case study. Radiol Phys Technol 2017; 10: 525-534. https://doi.org/10.1007/s12194-017-0431-4

[16] Ruggieri R, Stavrev P, Naccarato S, Stavreva N, Alongi F, Nahum AE. Optimal dose and fraction number in SBRT of lung tumours: A radiobiological analysis. Phys Med 2017; 44: 188-195. https://doi.org/10.1016/j.ejmp.2016.12.012

[17] Kim MS, Kim W, Park IH, Kim HJ, Lee E, Jung JH, Cho LC, Song CW. Radiobiological mechanisms of stereotactic body radiation therapy and stereotactic radiation surgery. Radiat Oncol J 2015; 33: 265-275. https://doi.org/10.3857/roj.2015.33.4.265

[18] Kutcher GJ, Burman C. Calculation of complication probability factors for non-uniform normal tissue irradiation: the effective volume method. Int J Radiat Oncol Biol Phys 1989; 16: 1623-1630. https://doi.org/10.1016/0360-3016(89)90972-3

[19] Kutcher GJ, Burman C, Brewster L, Goitein M, Mohan R. Histogram reduction method for calculating complication probabilities for three-dimensional treatment planning evaluations. Int J Radiat Oncol Biol Phys 1991; 21: 137-146. https://doi.org/10.1016/0360-3016(91)90173-2

[20] Seppenwoolde Y, Lebesque JV, De JK, Belderbos JS, Boersma LJ, Schilstra C, Henning GT, Hayman JA, Martel MK, Ten Haken RK. Comparing different NTCP models that predict the incidence of radiation pneumonitis. Normal tissue complication probability. Int J Radiat Oncol Biol Phys 2003; 55: 724-735.

https://doi.org/10.1016/S0360-3016(02)03986-X

[21] Chapet O, Kong FM, Lee JS, Hayman JA, Ten Haken RK. Normal tissue complication probability modeling for acute esophagitis in patients treated with conformal radiation therapy for non-small cell lung cancer. Radiother Oncol 2005; 77: 176-181.

https://doi.org/10.1016/j.radonc.2005.10.001

[22] Yang Y, Catalano S, Kelsey CR, Yoo DS, Yin FF, Cai J. Dosimetric effects of rotational offsets in stereotactic body radiation therapy (SBRT) for lung cancer. Med Dosim 2014; 39: 117-121.

https://doi.org/10.1016/j.meddos.2013.11.002

[23] Cozzi L, Dinshaw KA, Shrivastava SK, Mahantshetty U, Engineer R, Deshpande DD, Jamema SV, Vanetti E, Clivio A, Nicolini G, Fogliata A. A treatment planning study comparing volumetric arc modulation with RapidArc and fixed field IMRT for cervix uteri radiotherapy. Radiother Oncol 2008; 89: 180-191.

https://doi.org/10.1016/j.radonc.2008.06.013

[24] Zhai DY, Yin Y, Gong GZ, Liu TH, Chen JH, Ma CS, Lu J. RapidArc radiotherapy for whole pelvic lymph node in cervical cancer with 6 and $15 \mathrm{MV}$ : a treatment planning comparison with fixed field IMRT. J Radiat Res 2013; 54: 166-173. https://doi.org/10.1093/jrr//rss066

[25] Qiao L, Cheng J, Liang N, Xie J, Luo H, Zhang J. A comparative dosimetric study of volumetric-modulated arc therapy vs. fixed field intensity-modulated radiotherapy in postoperative irradiation of stage IB-IIA high-risk cervical cancer. Oncol Lett 2016; 11: 959-964. https://doi.org/10.3892/ol.2015.3998

[26] Ling CC, Gerweck LE, Zaider M, Yorke E. Dose-rate effects in external beam radiotherapy redux. Radiother Oncol 2010; 95: 261-268.

https://doi.org/10.1016/j.radonc.2010.03.014

[27] Klug F, Prakash H, Huber PE, Seibel T, Bender N, Halama N, Pfirschke C, Voss RH, Timke C, Umansky L, Klapproth K Schakel K, Garbi N, Jager D, Weitz J, Schmitz-Winnenthal H, Hammerling GJ, Beckhove P. Low-dose irradiation programs macrophage differentiation to an iNOS(+)/M1 phenotype that orchestrates effective $\mathrm{T}$ cell immunotherapy. Cancer Cell 2013; 24: 589-602. https://doi.org/10.1016/j.ccr.2013.09.014

[28] Prakash H, Klug F, Nadella V, Mazumdar V, SchmitzWinnenthal H, Umansky L. Low doses of gamma irradiation potentially modifies immunosuppressive tumor microenvironment by retuning tumor-associated macrophages: lesson from insulinoma. Carcinogenesis 2016; 37: 301-313.

https://doi.org/10.1093/carcin/bgw007

[29] Carretero R, Sektioglu IM, Garbi N, Salgado OC, Beckhove P, Hammerling GJ. Corrigendum: Eosinophils orchestrate cancer rejection by normalizing tumor vessels and enhancing infiltration of CD8(+) T cells. Nat Immunol 2016; 17: 214. https://doi.org/10.1038/ni0216-214b

[30] Arpaci F, Dogru T, Ozturk B, Komurcu S, Ozet A, Yilmaz MI Beyzadeoglu $M$, Turan M, Sengul A, Yalcin A. Changes in immunological recovery in patients who received posttransplant G-CSF or GM-CSF after autologous peripheral blood stem cell transplantation (PBSCT). Haematologia (Budap) 2002; 32: 253-264 https://doi.org/10.1163/15685590260461066

[31] de Gast GC, Vyth-Dreese FA, Nooijen W, van den Bogaard CJ, Sein J, Holtkamp MM, Linthorst GA, Baars JW, Schornagel JH, Rodenhuis S. Reinfusion of autologous lymphocytes with granulocyte-macrophage colonystimulating factor induces rapid recovery of CD4+ and CD8+ $\mathrm{T}$ cells after high-dose chemotherapy for metastatic breast cancer. J Clin Oncol 2002; 20: 58-64.

https://doi.org/10.1200/JCO.20.1.58

[32] Lachmann G, von HC, Kurth J, Yuerek F, Spies C. Innate immunity recovers earlier than acquired immunity during severe postoperative immunosuppression. Int $\mathrm{J}$ Med Sci 2018; 15: 1-9

https://doi.org/10.7150/ijms.21433

Received on 12-12-2019

Accepted on 24-12-2019

Published on 30-12-2019

https://doi.org/10.30683/1927-7229.2019.08.10

(C) 2019 Chairmadurai et al.; Licensee Neoplasia Research.

This is an open access article licensed under the terms of the Creative Commons Attribution Non-Commercial License (http://creativecommons.org/licenses/by-nc/3.0/) which permits unrestricted, non-commercial use, distribution and reproduction in any medium, provided the work is properly cited. 